\title{
VIBRATION DIAGNOSTICS OF SPIROID GEAR
}

\author{
Yury NIKITIN \\ Kalashnikov Izhevsk State Technical University \\ Pavol BOŽEK \\ Slovak University of Technology \\ Alexander TURYGIN \\ Kostroma State Agricultural Academy
}

\begin{abstract}
:
Spiroid gear is one of the progressive varieties of intersecting axis gears. It has a number of advantages: increased overlap coefficient, favourable contact conditions. Spiroid gears are notable for high loading and overloading ability, increased smooth running and less sensitivity to manufacturing and assembly errors, high reliability and durability. The analysis of the results of experiment on research of vibration of the spiroid gear PS- 124 has shown, that the vibration level at frequency $200-300 \mathrm{~Hz}$ is reduced on $5 \mathrm{~dB}$ at increase of the resistance moment up to $1000 \mathrm{Nm}$ at clockwise rotation of the reducer and at increase of the resistance moment up to $800 \mathrm{Nm}$ at counterclockwise rotation of the reducer. The vibration level at frequency $700-800 \mathrm{~Hz}$ is also increased on $5 \mathrm{~dB}$ at increase of the resistance moment up to $1000 \mathrm{Nm}$ at clockwise rotation of the reducer and at increase of the resistance moment up to $800 \mathrm{Nm}$. If these vibration levels are exceeded, a defect is likely to occur. Economic efficiency of application of diagnostics systems is caused by increase of reliability and quality, reduction of accidents, decrease in defects, reduction of idle time of expensive equipment, reduction of expenses for maintenance and repair.
\end{abstract}

Key words: spiroid gear, vibration, diagnostics

\section{INTRODUCTION}

Spiroid gear is one of the progressive varieties of intersecting axis gears. Due to a number of advantages of geometry and kinematics of meshing - increased overlap coefficient, favourable contact conditions - spiroid gears are characterized by high load and overload capacity, increased smooth running and less sensitivity to manufacturing and assembly errors, high reliability and durability [1].

Spiroid gearboxes are used in various fields, including pipeline equipment and oil refineries. Failure of a gearbox leads to great economic losses and environmental disasters. Therefore, diagnostics of spiroids reducers both at the stage of acceptance tests and during operation is an urgent task. Nowadays the number of such researches has increased, which proves the relevance of works on gearbox diagnostics.

In the last twenty years much attention has been paid to research in the field of vibration diagnostics. Signals are received from vibration sensors installed on the gearbox housing.

\section{LITERATURE REVIEW}

One of the leading scientific schools in the world for design and manufacture of spiroid gearboxes is the school of professor Veniamin Goldfarb [2, 3, 4, 5, 6, 7, 8, 9, 10, 11, 12]. The diagnostic technique consists in detecting signal changes caused by damage to gearbox parts $[12,13,14$, $15,16,17]$. Vibration signal modulations occur in the gearbox, as gearboxes mainly operate under harsh operating conditions [17]. Their major components such as gears and bearings are subject to damage such as fatigue cracking, pitting, corrosion, and wear and tear [18]. Even a small failure can lead to a disaster, so condition monitoring and diagnostic systems must be installed for gearboxes to detect the appearance of defects in time to avoid accidents, repairs and replacement of equipment. Faults can be detected by statistical analysis of the vibration signal [19].

The technique of change in gearmesh stiffness is widely used to study the vibratory property of the gearbox in gear dynamic modeling and computer simulation. The vi- 
bration response of the gearbox arrangement can be obtained analytically under various tooth fault conditions. It is also used to understanding the effect of the fault and system parameters on mesh stiffness in vibration diagnostic signal. To identify the condition of geared system a series of vibration signals can be generated through computer simulation analytically. Experiments can be conducted on single-stage and multistage gearboxes and vibration signals recorded for different levels of faults in gear tooth. The vibration response obtained from analytical model and experiments can be further analyzed by using different techniques available such as statistical and signal processing in the spectrum and its diagnostic performance is tested for comparative fault detection [20]. In [21] analysed methods for vibration diagnosis of electrical systems and gearboxes. In the case of gears, it can be noted that the oscillation of the gears is determined by the meshing frequency and harmonics due to the variable stiffness during meshing [22]. For a pair of damaged gears in gearboxes with fixed axles symmetrically around the meshing frequency and its harmonics, characteristic components and side bands appear in the frequency spectrum [23]. The vibration signal picked up by accelerometers mounted on the gearbox housing contains several types of vibrations from gears, shafts, bearings, etc. Informative vibration signals can easily be masked by strong background noise. Without noise reduction [24] it is therefore difficult to isolate faults in the low frequency range of the signal. Moreover, if a gearbox with several gearing pairs is involved, diagnosis becomes more difficult [25].

The informative components of the gearbox vibration spectrum, consisting of gearbox speed, gearing frequency and their harmonics, are affected by faults. Fault identification is associated with the appearance of a characteristic frequency associated with that fault. Similarly, different frequencies associated with different gears can be equated [26].

Gearbox vibration signals measured by accelerometers are in the time domain. If a gearbox malfunctions, the energy variation can be seen in the signal. A statistical measurement of the energy of the vibration signal is carried out to detect a malfunction. The various diagnostic techniques used use the vibration amplitude and energy of the signal in the time domain [27].

Modern condition monitoring techniques employ advanced technologies to evaluate the machine health and predict when and where the machine is likely to fail, thereby maximizing the machine profitability. Generally, vibration sensors are adopted for condition monitoring of rotating machinery or manufacturing processes. It is generally accepted that vibration signals from a gearbox depend on the sensor location relative to the source and are often contaminated by structure-borne noises from other sources, leading to a low signal noise ratio [27].

Gearbox is the major component that leads to turbine downtime. Its failures are mainly caused by the gearbox bearings. Devising condition monitoring approaches for the gearbox bearings is an effective predictive maintenance measure that can reduce downtime and cut maintenance cost. In [28] it is proposed a hybrid intelligent condition monitoring and fault warning system for wind turbine's gearbox.

The proposed framework encompasses the following:

a) clustering filter - (based on power, rotor speed, blade pitch angle, and wind speed signals) - using the automatic clustering model and ant bee colony optimization algorithm $(A B C)$,

b) prediction of gearbox bearing temperature and lubrication oil temperature signals - using variational mode decomposition, group method of data handling network, and multi-verse optimization algorithm, and

c) anomaly detection based on the Mahalanobis distances and wavelet transform denoising approach.

The proposed condition monitoring system was evaluated using $10 \mathrm{~min}$ average SCADA datasets of two $2 \mathrm{MW}$ onshore wind turbines located in the south of Sweden. The results showed that this strategy can diagnose potential anomalies prior to failure and inhibit reporting alarms in healthy operations [28].

\section{METHODOLOGY OF THE RESEARCH}

Experimental studies of highly loaded spiroid gear PS-124 were carried out at the scientific and production enterprise "Mekhanik" Ltd. of Kalashnikov Izhevsk State Technical University. Figure 1 shows the gearboxes produced by "Mekhanik" Ltd.

The tests were carried out on a test bench operating according to a closed circuit. The test bench consists of an electric drive with a gear reducer on the basis of a threephase asynchronous motor AIR80V4U2 at $1.6 \mathrm{~kW}$ power and $1395 \mathrm{rpm}$ speed, the studied spiroid gear PS-124, which has an input frequency of $45 \mathrm{rpm}$, a spuroid gear and a disk brake, which created the load torque, measured by a dynamometer DPU-0,2-2. A vibration sensor with a frequency range of $0-2000 \mathrm{~Hz}$ was fitted to the spiro gearbox via a magnet. The vibration data was fed into the LTR22 data acquisition system via the LE-41 charge amplifier and then displayed as a graph on the laptop screen.

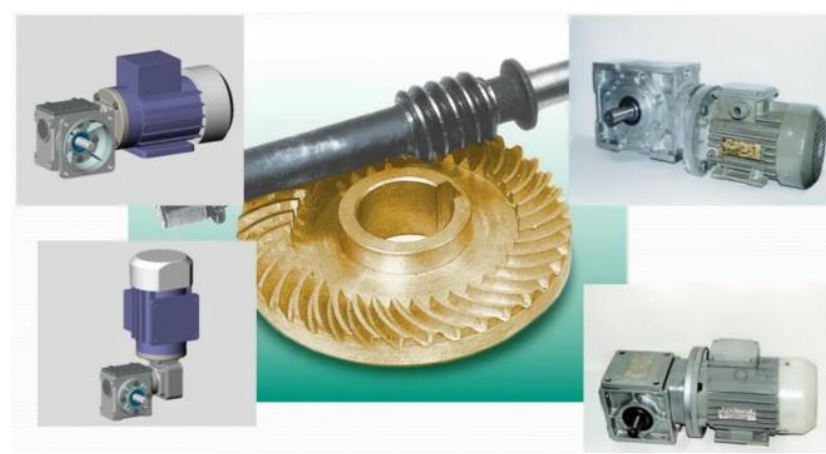

Fig. 1 Gearboxes produced by "Mekhanik" Ltd

Gearbox vibration was measured as the load varies from $200 \mathrm{Nm}$ to $1000 \mathrm{Nm}$, in steps of $200 \mathrm{Nm}$. Experiments were performed with the motor rotating in both directions. The spiroid gear PS-124 under investigation was subjected to 3000 running cycles: 2 revolutions, pause, 2 revolutions in the other direction and pause, which made 
12000 revolutions. The output speed of the spiroid gear was $21 \mathrm{rpm}$.

The structure of the test bench is shown in Fig. 2 .

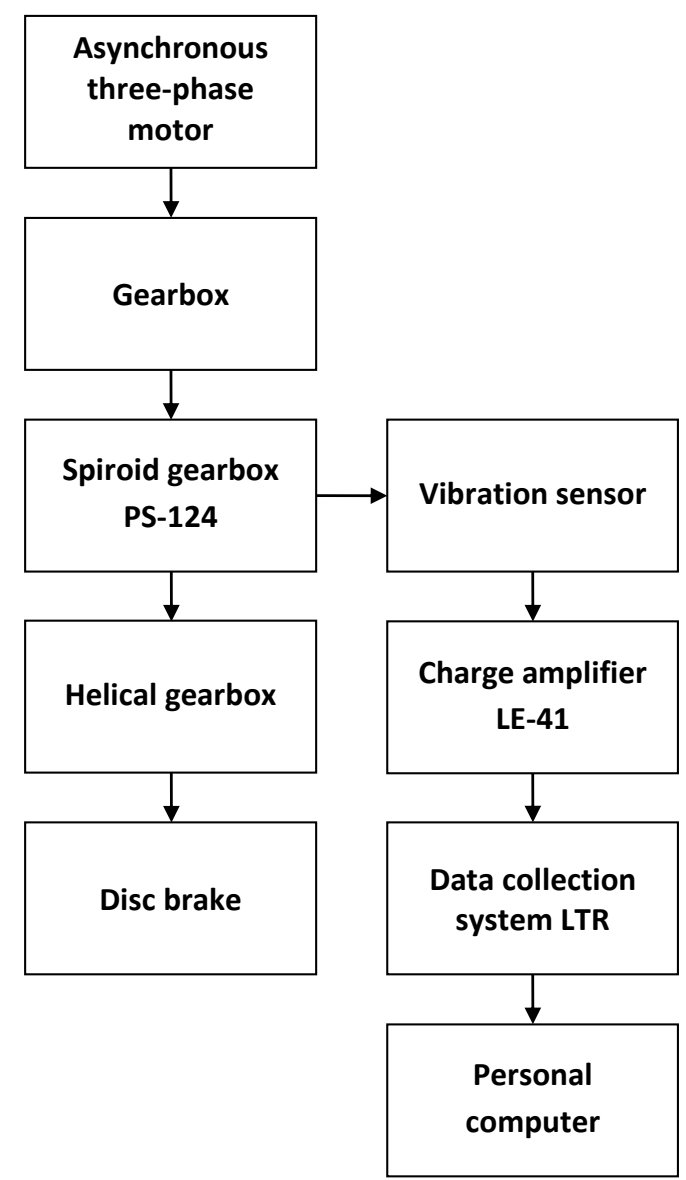

Fig. 2 Block diagram of the test bench

When carrying out an experimental vibration analysis, the type and technical characteristics of the sensors and their installation methods must be selected correctly. The way in which the sensors are mounted must not distort their specifications.

The locations for installing the vibration sensors (piezo accelerometers) should be selected so that the vibration sensor is as close to the gear zone as possible. Install the sensor in a location where the attenuation of the gear vibration is as low as possible. The distance between the vibration signals recorded from the gear zone and the vibration sensor should be as small as possible, especially in the case of gaps. The use of styli to mount the vibration sensors is not desirable, at least strong, rare-earth, permanent magnets should be used to mount the sensors on the gearbox.

The vibration sensor must be mounted in the direction of the line connecting the centres of the gearbox shafts or perpendicular to it.

For express diagnostics of gearboxes during acceptance tests it is reasonable to use magnetic fixing method with investigated frequency interval $0-2000 \mathrm{~Hz}$, providing fast installation, for stationary diagnostics systems - pin connection with investigated frequency interval $0-10000 \mathrm{~Hz}$, providing precise orientation at good machining. The overall view of the stand is shown in Fig. 3.

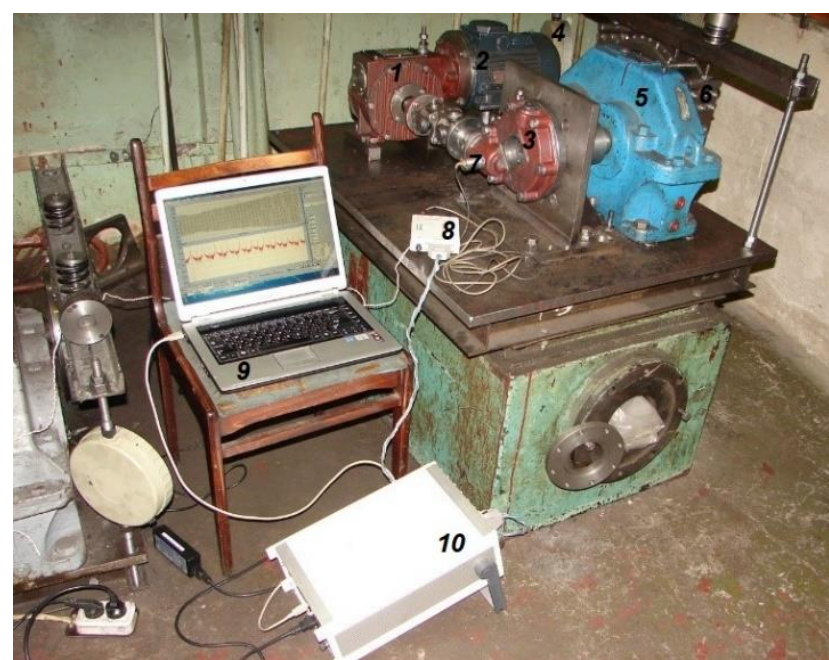

Fig. 3 General view of the stand:

1 - gearbox; 2 - asynchronous three-phase motor AIR 80V4U2;

3 - spiroid gear; 4 - dynamometer DPU-0,2-2; 5 - spur gearbox;

6 - disc brake; 7 - vibration sensor; 8 - charge amplifier LE-41; 9

- laptop; 10 - modular data acquisition system LTR

Fig. 4 shows the locations of the vibration sensors.

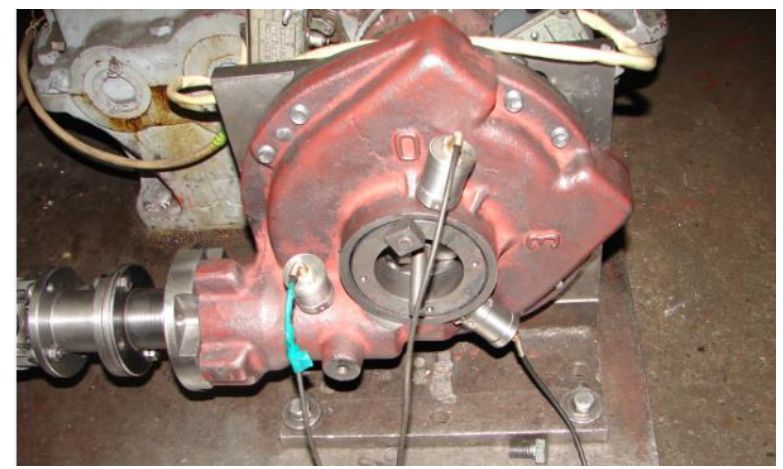

Fig. 4 Vibration sensor installation locations

\section{RESULTS OF EXPERIMENT ON VIBRATION MEASURE- MENT}

Figures 5, 6 show examples of spiroid gear vibration measurements with a $4000 \mathrm{Nm}$ load when the motor rotates in different directions.

Fig. 7 shows an example of $600 \mathrm{Nm}$ spiroid gear vibration measurements on the LTR Modular Data Acquisition System.

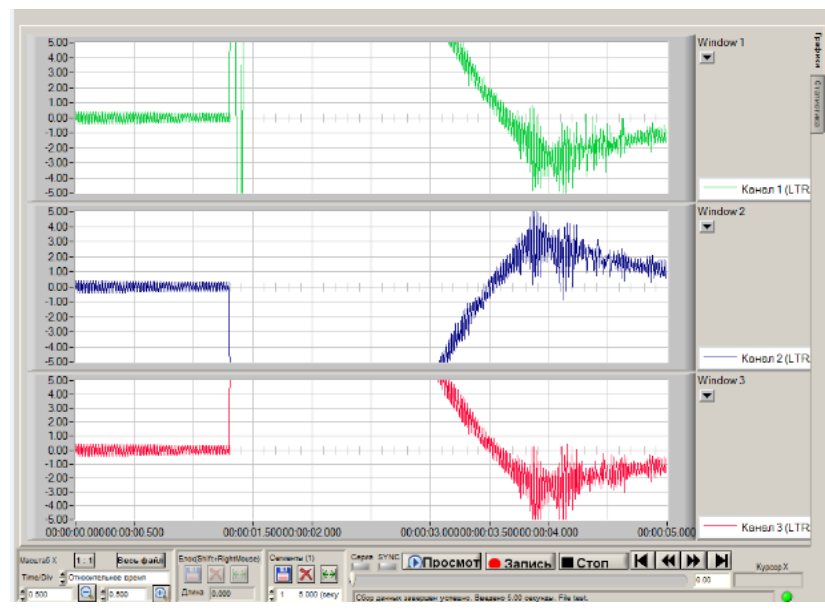

Fig. 5 Example oscilloscope of vibration for a spiroid gear with $4000 \mathrm{Nm}$ load, clockwise rotation 


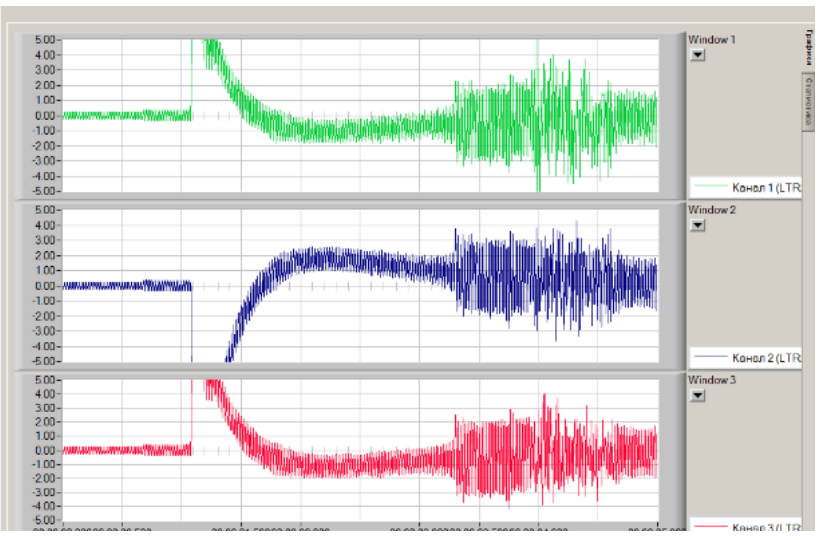

Fig. 6 Example oscilloscope of vibration for a spiroid gear with $4000 \mathrm{Nm}$ load, anti-clockwise rotation

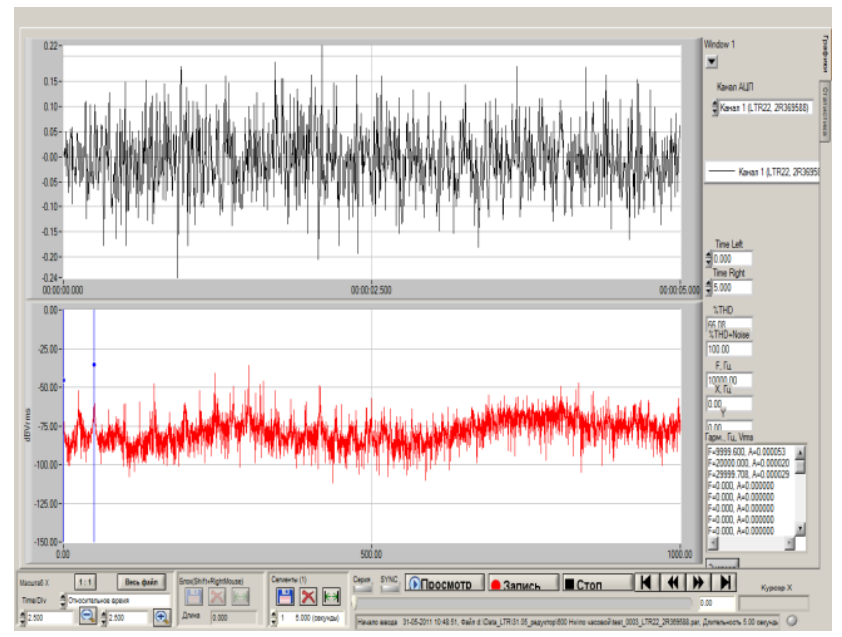

Fig. 7 Example of oscillogram and vibration spectrum for spiroid gear with $600 \mathrm{Nm}$ load torque

Table 1 shows the experimental results for the low frequency vibration of the spiroid gear PS-124.

Table 1

Results of experiment on measurement of low-frequency vibration (200-300 Hz) of the spiroid gear PS-124

\begin{tabular}{|l|c|c|c|c|c|}
\hline Load torque, Nm & 200 & 400 & 600 & 800 & 1000 \\
\hline $\begin{array}{l}\text { Amplitude of low-frequency vibra- } \\
\text { tion 200-300 Hz with clockwise rota- } \\
\text { tion of the gearbox, dB }\end{array}$ & -60 & -60 & -60 & -60 & -65 \\
\hline $\begin{array}{l}\text { Amplitude of low-frequency vibra- } \\
\text { tion 200-300 Hz with counter-clock- } \\
\text { wise rotation of the gearbox, dB }\end{array}$ & -60 & -60 & -60 & -70 & -70 \\
\hline
\end{tabular}

Table 2 shows the experimental results for the medium frequency vibration of the spiroid gear PS-124.

Table 2

Results of experiment to measure mid-frequency vibration $(700-800 \mathrm{~Hz})$ of the spiroid gear PS-124

\begin{tabular}{|l|c|c|c|c|c|}
\hline Load torque, Nm & 200 & 400 & 600 & 800 & 1000 \\
\hline $\begin{array}{l}\text { Amplitude of mid-frequency vibration } \\
700-800 \mathrm{~Hz} \text { with clockwise rotation of } \\
\text { the gearbox, } \mathrm{dB}\end{array}$ & -70 & -60 & -60 & -60 & -55 \\
\hline $\begin{array}{l}\text { Amplitude of mid-frequency vibration } \\
700-800 \mathrm{~Hz} \text { with counter-clockwise ro- } \\
\text { tation of the gearbox, } \mathrm{dB}\end{array}$ & -60 & -60 & -60 & -55 & -55 \\
\hline
\end{tabular}

\section{CONCLUSIONS}

Spiroid gears are notable for high loading and overloading ability, increased smooth running and less sensitivity to manufacturing and assembly errors, high reliability and durability.

The analysis of results of the experiment on investigation of vibration of the spiro gearbox PS-124 shows that the vibration level at frequency $200-300 \mathrm{~Hz}$ is reduced by $5 \mathrm{~dB}$ with an increase of the resistance moment up to $1000 \mathrm{Nm}$ by clockwise rotation of the gearbox and an increase of the resistance moment up to $800 \mathrm{Nm}$ by counter-clockwise rotation of the gearbox.

The vibration level at frequency $700-800 \mathrm{~Hz}$ is increased by $5 \mathrm{~dB}$ with an increase of the resistance moment up to $1000 \mathrm{Nm}$ by clockwise rotation of the gearbox and an increase of the resistance moment up to $800 \mathrm{Nm}$ by clockwise rotation of the gearbox. At excess of the given vibration levels the probability of occurrence of defect is high. Economic efficiency of application of diagnostic systems is conditioned by increase of reliability and quality, reduction of accidents, decrease in defects, reduction of downtime of expensive equipment, reduction of maintenance and repair costs.

\section{ACKNOWLEDGMENTS}

This article was supported by the scientific grant agency of the Slovak Republic under the grant Accurate calculations, modeling and simulation of new surfaces based on physical causes of machined surfaces and additive technology surfaces in machinery and robotical machining conditions no. 1/0097/20 and Progressive form of interdisciplinary education and support for the development of the study of vocational subjects in the university environment no. 006STU-4/2021.

\section{REFERENCES}

[1] Y.G. Lei, J. Lin, M.J. Zou, Z.J. He. "Condition monitoring and fault diagnosis of planetary gearboxes: a review ". Measurement, 48, 2014, pp. 292-305.

[2] E.S. Trubachev, V.N. Anferov, I.V. Shishlova. "Calculation of Forces in Spiroid Gearing Using the Results of Physical Modeling". Vestnik IzhGTU imeni M.T. Kalashnikova, 2021, vol. 24 , no. 2, pp. $77-84$ (in Russ.). doi: 10.22213/24131172-2021-2-77-84.

[3] S. Maláková, P. Frankovský, D. Harachová, V. Neumann. "Design of construction optimisation determined for mixed truck gearbox". Ad Alta: Journal of Interdisciplinary Research, 9(2), 2019.

[4] S. Maláková, M. Puškár, P. Frankovský, S. Sivák, M. Palko, M. Palko. "Meshing Stiffness - A Parameter Affecting the Emission of Gearboxes". Applied Sciences, 10(23), 2020, 8678.

[5] M. Saga, V. Bulej, N. Cubonova, I. Kuric, I. Virgala, M. Eberth. "Case study: Performance analysis and development of robotized screwing application with integrated vision sensing system for automotive industry" International Journal of Advanced Robotic Systems, Vol. 17, Issue 3, doi: 10.1177/1729881420923997

[6] I.A. Pushkarev, A.V.Ovsyannikov. "Research of Load Distribution on Rollers of the K-H-V Planetary Gear". Vestnik IzhGTU imeni M.T. Kalashnikova, 2021, vol. 24, no. 1, pp. 31-37 (in Russ.). doi: 10.22213/2413-1172-2021-1-31-37. 
[7] V. Goldfarb, E. Trubachev, N. Barmina (Eds.) Advanced Gear Engineering. Springer International Publishing AG Switzerland, Vol. 51, 2018, 497 p. doi: 10.1007/978-3-31960399-5.

[8] V. Goldfarb, E. Trubachev, N. Barmina (Eds.) New approaches to gear design and production. Springer International Publishing AG Switzerland, Vol. 81, 2020, 529 p. doi: 10.1007/978-3-030-34945-5.

[9] V. Goldfarb, E. Trubachev, N. Barmina. "Innovations in design and production of spiroid gears in the XXI century". MATEC Web of Conferences 287, 01002, 2019, doi: 10.1051/matecconf/201928701002.

[10] V. Goldfarb, E. Trubachev, T. Pushkareva, T. Savelyeva. "Comparative investigation of worm and spiroid gears with cylindrical worms". In: Advances in Mechanism and Machine Science. IFToMM WC 2019. Mechanisms and Machine Science, vol 73. Springer, Cham. 2019, pp. 925-935. doi: 10.1007/978-3-030-20131-9_92.

[11] V.I. Goldfarb, E.S. Trubachev, K.V. Bogdanov et al. "Prospects of manufacturing spiroid gears with small gear ratios". Forsch Ingenieurwes, 2019, 83, pp. 781-791. doi: 10.1007/s10010-019-00343-8.

[12] K. Sentyakov, J. Peterka, V. Smirnov, P. Božek, V. Sviatskii. "Modeling of Boring Mandrel Working Process with Vibration Damper". Materials. Vol. 13, iss. 8, 2020, pp. 1-13. ISSN 1996-1944. doi: 10.3390/ma13081931.

[13] O. Matsushita, M. Tanaka, M. Kobayashi, P. Keogh, H. Kanki. Vibrations of Rotating Machinery. Vol. 2. Advanced Rotordynamics: Applications of Analysis, Troubleshooting and Diagnosis. 2019. Springer Japan KK. 577 p. doi: 10.1007/978-4-431-55453-0.

[14] Yu. Nikitin, P. Bozek, J. Peterka. "Logical-linguistic Model of Diagnostics of Electric Drivers with Sensors Support". Sensors, 2020, 20, 4429. doi: 10.3390/s20164429.

[15] V. Sharmaa, A. Pareya. "A review of gear fault diagnosis using various condition indicators". Procedia Engineering, 144, 2016, pp. 253-263.

[16] A. Hammami, M. Iglesias, A. Fernandez, F. Chaari, F. Viadero, M. Haddar. "Load sharing behavior in planetary gear set". In: Multiphysics Modelling and Simulation for Systems Design and Monitoring Applied Condition Monitoring, vol. 2, 2017, pp. 459-468. doi: 10.1007/978-3-31914532-7_47.

[17] J. Peterka, P. Bozek, Yu. Nikitin. "Diagnostics of automated technological devices". MM Science Journal, oct. 2020, pp. 4027-4034. doi: 10.17973/MMSJ.2020_10_2020051.

\section{Yury Nikitin}

Kalashnikov Izhevsk State Technical University

Student Street 7, Izhevsk, 426069

Udmurt republic, Russia

e-mail: nikitin@istu.ru

\section{Pavol Božek}

Slovak University of Technology

Faculty of Materials Science and Technology

Institute of Applied Informatics,

Automation and Mechatronics

Jána Bottu č. 2781/25, 91724 Trnava, Slovak Republic

e-mail: pavol.bozek@stuba.sk
[18] A.W Lees. Vibration Problems in Machines: Diagnosis and Resolution. CRC Press, Taylor \& Francis Group, 2016. XVI, 321 p. ISBN 978-1-4987-2675-7.

[19] B. Cai. Bayesian Networks in Fault Diagnosis Practice and Application. Singapore: World Scientific, 2019. 418 p.

[20] H. Malik, A. Iqbal, K.A. Yadav (Eds.) Soft Computing in Condition Monitoring and Diagnostics of Electrical and Mechanical Systems: Novel Methods for Condition. Springer, 2020, 499 p. Advances in Intelligent Systems and Computing 1096. ISBN 981151531X.

[21] S. Trefilov, P. Bozek, Nikitin Y, Martinovic J., Peterka J. Diagnostics of actuators of machine tools drives according to the identifiability criterion by the state space. MM Science Journal, 2021, pp. November, pp. 5291-5296. doi: 10.17973/MMSJ.2021_11_2021131.

[22] Mustafa D., Muhammet U. (eds.) Fault Diagnosis and Detection. ExLi4EvA, 2017, 35 p. ISBN-13 978-953-51-3203-5.

[23] P. Božek, Yu. Nikitin, T. Krenicky. "Diagnostics of Mechatronic Systems". Series: Studies in Systems, Decision and Control 345. Springer Nature, Switzerland AG. 2021, 79 p. doi: 10.1007/978-3-030-67055-9.

[24] A. Felkaoui, F. Chaari., M. Haddar (eds.) Rotating Machinery and Signal Processing. New York: Springer, 2019, 142 p.

[25] B.H. Chudnovsky. Transmission, Distribution, and Renewable Energy Generation Power Equipment: Aging and Life Extension Techniques. CRC Press, Taylor \& Francis, 2017, 677 p. (Second edition). ISBN 101498754759/ISBN 13 9781-4987-5475-0.

[26] E. Kuzin, B. Gerike, M. Mamaeva, K. Singh. "Diagnostics of Gearboxes of Mining Belt Conveyors Using Floating Spectral Masks". In E3S Web of Conferences, Jan. 2019, 105:03011. doi: 10.1051/e3sconf/201910503011.

[27] K. Lu, J.X. Gu, H. Fan., X. Sun, B. Li., F. Gu. "Acoustics Based Monitoring and Diagnostics for the Progressive Deterioration of Helical Gearboxes". Dec. 2021, Chinese Journal of Mechanical Engineering, 34(1). doi: 10.1186/s10033-02100603-1.

[28] A. Heydari, D.A. Garcia, A. Fekih, F. Keynia., L.B. Tjernberg, L.D. Santoli. "A Hybrid Intelligent Model for the Condition Monitoring and Diagnostics of Wind Turbines Gearbox". Jun. 2021, IEEE Access PP(99):1-1. doi: 10.1109/ACCESS.2021.3090434.

\author{
Alexander Turygin \\ Kostroma State Agricultural Academy \\ Department Repair and Basics of Machine Design \\ Training town 34, Kostroma region, \\ Karavaevo 156530, Russia \\ e-mail: ab.turygin@yandex.ru
}

